\title{
Endoscopic Treatment of GERD and Case Report: Successful Anti-Reflux Mucosectomy (ARMS) For Endoscopic Treatment of PPI-Resistant GERD in A 24-Years-Old Greek
}

\author{
Nikolas Eleftheriadis ${ }^{1,2}$, MD Haruhiro Inoue ${ }^{1}$, MD PhD, Haruo Ikeda ${ }^{1}$, MD Manabu Onimaru ${ }^{1}$, MD Grace Santi ${ }^{1}$ \\ and MD Roberta Maselli ${ }^{1}$ \\ ${ }^{1}$ Digestive Diseases Center, Showa University, Japan \\ ${ }^{2}$ Gastroenterology Department, Metropolitan Hospital Athens, Greece \\ Submission: January 31, 2017; Published: February 07, 2017 \\ "Corresponding author: Nikolas Eleftheriadis, Digestive Diseases Center, Showa University, Koto Toyosu Hospital, 5-1-38 Toyosu, Koto-ku, Tokyo \\ 135-8577, Japan, Tel: +81-3-6204-6000; Fax: +81-3-62046396; E-mail: nikoseleftheriadis@yahoo.com
}

Abstract

Aim: To present an update of the endoscopic therapies of GERD and to discuss further developments.

Methods: A PubMed search was performed. Also, we report our experience from the successful application of antireflux mucosectomy (ARMS), a recent endoscopic technique for GERD, in a young Greek female with refractory to PPIs GERD and severe respiratory symptoms, who showed excellent long-term results one-year after ARMS, with low morbidity, hospitalization time and cost.

Results: Currently, there are 3 commonly employed anti-reflux endoluminal procedures: a) fundoplication or suturing techniques (EndoCinch, NDO, and EsophyX), b) intramural injection or implant techniques (enhancing lower esophageal sphincter (LES) volume and/ or strengthening compliance of the LES (Enteryx and Gatekeeper), and c) radiofrequency energy deliver to LES and cardia (Stretta). Although all three techniques were able to improve symptoms, the quality of life, PPI use and esophageal acid reduction were unremarkable. Endocinch and Stretta are safe outpatient procedures. Polymer injection (Enteryx) and gel prosthesis implantation (Gatekeeper) were recalled for severe complications and lack of efficacy, respectively. No single endoscopic modality has been yet proved or accepted as the endoscopic therapy of choice for GERD. Recently, antireflux mucosectomy (ARMS), based on natural scar formation after healing of the mucosal defect, has been described as miniinvasive, effective endoscopic treatment for PPI-resistant GERD, with no need of insertion or implantation of any foreign instruments into the lower esophagus.

Conclusion: Endotherapy has shown the potential to treat uncomplicated GERD. However, some early procedures have failed or proven unsafe. Further developments and studies are necessary to determine what modifications to these techniques are required to produce optimal efficacy and durability. Finally, ARMS showed promising results as the minimally invasive, endoscopic treatment for GERD in pioneering centers. However, long-term results from greater number of patients are necessary and awaited.

\section{Endoscopic Treatment of GERD}

\section{Background}

Gastroesophageal reflux disease (GERD) is defined as symptoms or mucosal damage produced by the abnormal reflux of gastric contents into the esophagus. Medical, endoscopic, and open/laparoscopic surgical methods are used to treat GERD. Over the last years a number of endoscopic procedures (suturing, injections, implants and radiofrequency energy application), have been developed for treating GERD, thus obviating the need for long-term proton pump inhibitors (PPI) and the potential morbidity of laparoscopic fundoplication.

Aim: To present an update of the endoscopic therapies of GERD and to discuss further developments.

Methods: A PubMed search was performed for $<<$ endoscopic suturing $>>, \quad<<$ antireflux treatment $>>, \quad<$ endoscopic gastroplication $>>$, $<<$ polymer injection $>>, \quad<<$ radiofrequency ablation $>>$ for GERD. Also, we report our experience from the 
successful application of antireflux mucosectomy (ARMS [1]), a recent endoscopic technique for GERD, in a young Greek female with refractory to PPIs GERD and severe respiratory symptoms, who showed excellent long-term results one-year after ARMS, with low morbidity, hospitalization time and cost.

Results: Currently, there are [2,3] commonly employed anti-reflux endoluminal procedures (Table 1): a) fundoplication or suturing techniques (EndoCinch [2], NDO [3], and EsophyX [4]), b) intramural injection or implant techniques (enhancing lower esophageal sphincter (LES) volume and/or strengthening compliance of the LES (Enteryx and Gatekeeper) [5,6], and c) radiofrequency energy deliver to LES and cardia (Stretta $[7,8]$ ).

Table 1: Endoscopic treatment options for GERD.

\begin{tabular}{|c|c|}
\hline Therapy & Features \\
\hline 1. ARMS & $\begin{array}{l}\text { Outpatient; Endoscopic; Easy to perform; no } \\
\text { foreign bodies implantation; Mucosectomy and scar } \\
\text { formation; Need further studies. }\end{array}$ \\
\hline 2. Stretta & $\begin{array}{c}\text { Outpatient; Endoscopic; Easy to perform; Good } \\
\text { efficacy and safety; radiofrequency; Minimal side } \\
\text { effects }\end{array}$ \\
\hline 3. EndoCinch & $\begin{array}{l}\text { Outpatient; Endoscopic; difficult to perform; good } \\
\text { long-term efficacy and safety; suturing technique; } \\
\text { Minimal side effects }\end{array}$ \\
\hline $\begin{array}{l}\text { 4. NDO } \\
\text { Plicator }\end{array}$ & $\begin{array}{c}\text { Outpatient; Endoscopic; difficult to perform; good } \\
\text { long-term efficacy and safety; Intraluminal full } \\
\text { thickness fundoplication technique; Minimal side } \\
\text { effects }\end{array}$ \\
\hline 5. Enteryx & $\begin{array}{l}\text { Outpatient; Endoscopic; difficult to perform; } \\
\text { intramural injection technique; Recalled. }\end{array}$ \\
\hline 6. Gatekeeper & $\begin{array}{l}\text { Outpatient; Endoscopic; difficult to perform; } \\
\text { intramural implantation technique; Recalled. }\end{array}$ \\
\hline
\end{tabular}

Although all three techniques were able to improve symptoms, the quality of life and PPI use, esophageal acid reduction were unremarkable. Endocinch and Stretta are safe outpatient procedures $[2,6,8]$. Concerns about the durability of Endocinch have risen [9], Polymer injection (Enteryx [4]) and gel prosthesis implantation (Gatekeeper [6]) were recalled for severe complications and lack of efficacy, respectively.

Uncontrolled studies have reported promising clinical results on the short to intermediate term for most endoscopic GERD procedures, but the placebo effect remained unknown [9], while no single endoscopic modality has been yet proved or finally accepted as the more efficacious or is considered as the endoscopic therapy of choice.

Recently, antireflux mucosectomy (ARMS) [1], based on natural scar formation after healing of the mucosal defect, has been described as miniinvasive, effective endoscopic treatment for PPI-resistant GERD, without large hiatal hernia, with no need of insertion or implantation of any foreign instruments into the lower esophagus.

\section{Case Report}

$<<$ Successful anti-reflux mucosectomy (ARMS) for endoscopic treatment of PPI-resistant GERD in a 24-years-old Greek >>

We report on a 25-years-old female with 3-years history of PPIresistant GERD, with esophagitis Los Angeles (LA) classification type II, serious respiratory symptoms and histological findings of non-dysplastic Barrett esophagus successfully treated by ARMS. Patient continued to have respiratory and reflux symptoms despite long-term high PPI-doses (pantoprazole 40mg twice daily), with significant deterioration of her quality of life and decided to go further to either surgical fundoplication or other endoscopic treatment.

ARMS proposed as less invasive endoscopic treatment, with low recovery time, which was accepted and subsequently performed in the endoscopy department, under conscious sedation. Piecemeal endoscopic mucosal resection with cup (EMR-C) technique [10] was used to complete a semicircumferential ARMS, including one $\mathrm{cm}$ above and two $\mathrm{cm}$ below the gastro esophageal junction (GEJ) and with no more than $2 / 3$ of the cardia circumference to prevent severe stenosis, according to initial description by Inoue, et al. [1] (Figure $1 \mathrm{~A}-\mathrm{C}$ ).

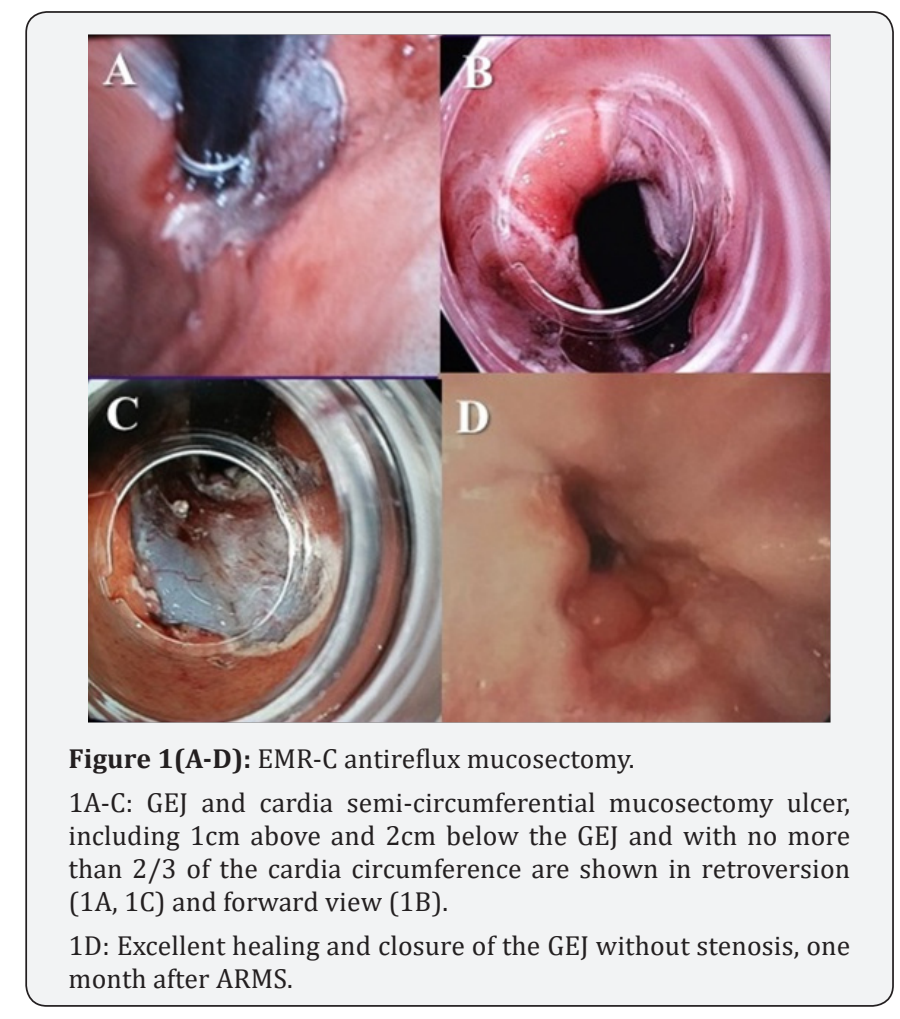

Four snares [10] were used and total eight mucosectomy pieces were removed. No major acute or late complications were reported, particularly no bleeding or perforation. Patient recovered uneventfully and discharged one day after. She began liquid diet the day after and gradually increased to soft diet. She returned to her usual activities three days later. She complained of mild chest pain during the first week after ARMS, easily 
controlled by common analgesics and received high PPI-doses for 40 days. Control endoscopy one month after ARMS showed excellent healing and closure of the GEJ without any sign of stenosis (Figure 1D). During one-year follow-up post-ARMS, the patient is asymptomatic, reported no GERD or respiratory symptoms and stopped the PPIs.

According to our experience, from the successful application of ARMS, although in only one patient, we consider ARMS as easy, safe and effective, endoscopic treatment for PPI-resistant GERD, with low morbidity, hospitalization time and cost, with excellent outcome remained in long-term. However, longer follow-up and greater number of patients from pioneering centers are awaited for this promising, miniinvasive, endoscopic treatment for GERD.

\section{Conclusion}

Endotherapy has shown the potential to treat uncomplicated GERD. However, some early procedures have failed or proven unsafe. Further developments and studies are necessary to determine what modifications to these techniques are required to produce optimal efficacy and durability. Finally, ARMS showed promising results as the minimally invasive, endoscopic treatment for GERD in pioneering centers, without the need of insertion or implantation of any foreign instruments into the lower esophagus.

\section{References}

1. Inoue H, Ito H, Ikeda H, Sato C, Sato H, et al. (2014) Anti-reflux mucosectomy for gastroesophageal reflux disease in the absence of hiatus hernia: a pilot study. Ann Gastroenterol 27: 346-351.
2. Yew KC, Chuah SK (2013) Antireflux endoluminal therapies: past and present. Gastroenterol Res Pract 2013: 481417.

3. Chen D, Barber C, McLoughlin P, Thavaneswaran P, Jamieson GG, et al. (2009) Systematic review of endoscopic treatments for gastrooesophageal reflux disease. Br J Surg 96: 128-136.

4. Pandolfino JE, Krishnan K (2014) Do endoscopic antireflux procedures fit in the current treatment paradigm of gastroesophageal reflux disease? Clin Gastroenterol Hepatol 12: 544-554.

5. Devière J, Costamagna G, Neuhaus H, Voderholzer W, Louis H, et al. (2005) Nonresorbable copolymer implantation for gastroesophageal reflux disease: a randomized sham-controlled multicenter trial. Gastroenterology 128(3): 532-540.

6. Schwartz MP, Smout AJ (2007) Review article: The endoscopic treatment of gastro-oesophageal reflux disease. Aliment Pharmacol Ther 26(Suppl)2: 1-6.

7. Franciosa M, Triadafilopoulos G, Mashimo H (2013) Stretta Radiofrequency Treatment for GERD: A Safe and Effective Modality. Gastroenterol Res Pract 2013: 783815.

8. Triadafilopoulos G (2007) Endotherapy and surgery for GERD. J Clin Gastroenterol 41(Suppl 2): S87-S96.

9. Danalioglu A, Cipe G, Toydemir T (2014) Endoscopic stapling in comparison to laparoscopic fundoplication for the treatment of gastroesophageal reflux disease. Dig Endosc 26(1): 37-42.

10. Inoue H, Takeshita K, Hori H (1993) Endoscopic mucosal resection with a cap-fitted panendoscope for esophagus, stomach, and colon mucosal lesions. Gastrointest Endosc 39(1): 58-62.

\section{Your next submission with Juniper Publishers will reach you the below assets}

- Quality Editorial service

- Swift Peer Review

- Reprints availability

- E-prints Service

- Manuscript Podcast for convenient understanding

- Global attainment for your research

- Manuscript accessibility in different formats ( Pdf, E-pub, Full Text, Audio)

- Unceasing customer service

Track the below URL for one-step submission https://juniperpublishers.com/online-submission.php 